REVIEW

\title{
Catalytic hydrothermal upgrading of pyrolysis oil
}

\author{
Moses Otieno Apunda ${ }^{1 *}$, Daniel Ogenga ${ }^{2}$ \\ ${ }^{1}$ University of Leeds, Leeds, United Kingdom \\ ${ }^{2}$ Masinde Muliro University of Science and Technology, Kakamega, Kenya \\ *Corresponding Author: Moses Otieno Apunda: mostecheng@gmail.com
}

\section{OPEN ACCESS}

Citation: Apunda M.O., Ogenga D. (2016) Catalytic hydrothermal upgrading of pyrolysis oil. Open Science Journal 1(3)

Received: $22^{\text {nd }}$ April 2016

Accepted: $27^{\text {th }}$ June 2016

Published: $8^{\text {th }}$ November 2016

Copyright: (C) 2016 This is an open access article under the terms of the Creative Commons Attribution License, which permits unrestricted use, distribution, and reproduction in any medium, provided the original author and source are credited.

Funding: The author(s) received no specific funding for this work.

Competing Interests: The author have declared that no competing interests exists.

\section{Abstract}

Pyrolysis oil from wood pellets was upgraded in this research by catalytic hydrotreatment in a $100 \mathrm{ml}$ batch reactor. Four heterogeneous $5 \%$ metal catalysts ( $\mathrm{Ru}, \mathrm{Ni}, \mathrm{Rh}$, and $\mathrm{Ni}$ ) were used at different hydrotreatment temperatures $\left(250{ }^{\circ} \mathrm{C}\right.$ and 300 $\left.{ }^{o} \mathrm{C}\right)$. Two different set-ups were also used with formic acid and with only bio-oil. The products of the reforming using two temperature conditions were then analysed and compared. The results showed that higher temperature yielded a lot of char compared to lower temperature giving low bio-oil recovery and poor carbon yield in the bio-oil. Also higher temperature resulted into the production of more carbon dioxide gas and hydrocarbon gases. $\mathrm{Ru}$ catalyst appeared to be the best among all the catalysts in reducing the amount oxygen wt- $\%$ by $42.12 \%$ at 250 ${ }^{\mathrm{o}} \mathrm{C}$. Ru treated bio-oil also registered the highest composition of the lightest compounds of about $88.5 \%$ compared to initial biooil which only had $30.6 \%$. Elemental analyses results show that all the upgraded bio-oils displayed lower oxygen content than the raw bio-oil with increased hydrogen and carbon composition.

Keywords: Hydrodeoxygenation, Decarboxylation, Carbonylation, Temperature, Bio-oil 


\section{Introduction}

There has been a higher decline in the easily available fossil fuels and as well, with their availability; there is serious concern about the carbon dioxide and nitrogen dioxide emissions any time such fuels are burnt (Parapati and Steele, 2014). Carbon dioxide poses serious threat to the atmospheric environment and can lead to global warming and, nitrogen dioxide emission can lead to acidic rain which is detrimental to the natural environment and can as well involve in stratospheric ozone reactions and lead to climate change. There is urgent need for scientific research to come up with a sustainable energy resource which can save the earth from the global warming menace and allow environmental sustainability. Biomass is indeed considered as the most promising resource since it is very abundant and sustainable (Carpenter et al., 2014). Biomass can therefore be used to produce environmental friendly liquid fuel via a number of technological processes such as pyrolysis. Biomass is very complex in nature but consists of very minimal amounts of nitrogen, sulphur and ash. Burning biomass derived fuels therefore has very minimal environmental degradation compared to the fossil fuels which emits large quantities of harmful gases into the environment such as carbon dioxide, soot and nitrogen oxides (NOX). Currently, carbon dioxide has turned to be the most dangerous gaseous emission causing climate change. Biomass has attracted a lot of attention worldwide in the energy sector especially due to the fact that it can help in reducing the global warming challenge caused by carbon dioxide (CO2) since it has very minimal gaseous emissions (Zhang et al., 2007). Biomass derived fuels when burnt produces zero or negative carbon dioxide emissions due to the fact that, plants can be grown anywhere and utilises CO2 produced when biomass derived fuels are burnt during the photosynthesis process. This makes biomass sustainable (Tsai et al., 2007).

\section{Biomass conversion processes}

Biomass can either be from municipal waste, remnants of harvested wood, straw or other plant stalks which all have to be well prepared before being converted into liquid fuel. Preparation of biomass feedstock is very necessary to render it denser and give it physical characteristics (Carpenter et al., 2014). This can be done using appropriate analytical technique to identify the properties of the biomass or solid waste before proper conversion method is chosen. Several processes are available to convert biomass into energy useful products. Such processes can be biological, mechanical or thermal applications. The thermal processes include; pyrolysis, gasification, liquefaction and combustion (Parapati and Steele, 2014). Pyrolysis of biomass has gained momentum than other thermal conversion processes since it produces liquid, solid and gaseous products directly by thermal decomposition in the absence of oxygen (Bridgwater, 2012). Key to this project's interest is the bio-oil which is a pyrolysis product. Bio-oil has wide range of uses in the energy sector but as well, it is still faced with a number of challenges resulting from some of the undesirable qualities it exhibits.

\section{Quality and composition of bio-oil}

Bio-oil composition is dependent on the feedstock type, the type of the pyrolysis and the condition under which pyrolysis is undertaken (Balat et al., 
2009). Maschio et al. (1992) performed conventional pyrolysis research with different feed stocks and noted that bio-oil from different materials possess varying chemical properties alongside their heating values. Bio-oil has the potential of being used as fuel oil substitute since several tests indicates that such oils burns effectively in modified engines and boilers just like the commercial fuels. The heating value lies between $40 \%$ and $50 \%$ of that for hydrocarbon fuels (Yaman, 2004). Huber et al., 2006 reported other pyrolysis oil qualities as; 15 w\%, carbon 54-56 wt\%, hydrogen 5.5-7\%, 35-40 wt\% with higher heating value of 16-19 MJ/kg. Bio-oil also has variety of complex chemical compounds in it with about $15-30 \%$ water insoluble lignin fragments, $20-30 \%$ water, $5-10 \%$ carbohydrates, 2-5\% alcohols, 1-5\% ketones, 10-15\% organic acids, 10-20\% aldehydes, 2-5\% phenolics and 1-4\% furfurals (Grirard and Blin, 2005). Due to this complexity, its characterisation still remains to be a challenge.

Having analysed the possible causes of the undesirable qualities of the bio-oil, this project therefore aims at upgrading pyrolysis oil into liquid transport fuel using catalytic hydrothermal reforming. The experiment will use appropriate analytical methods to characterise bio-oil, its properties and the products of reforming process. The catalysts used and the influence of temperature on hydrothermal upgrading is investigated.

\section{Materials And Methods}

\section{Batch reactor}

The experiment was carried out in a stainless pressurised batch reactor manufactured by Parr Instruments Company, USA. The reactor had a volume capacity of $100 \mathrm{ml}$. The maximum designed operational temperature of the reactor is $350{ }^{\circ} \mathrm{C}$ while designed maximum operational pressure is 150 bars (2250 psi). The reactor was supplied with a $1.4 \mathrm{~kW}$ ceramic heater obtained from Elmatic Limited, Cardiff, UK. Figure 1 shows the components of the batch reactor. For safety reasons due to any excess pressure that may develop, the reactor is fitted with a rupture disc to release any excess pressure. The reactor has two $\mathrm{J}$ - thermocouples fitted in stainless steel sheath. One thermocouple is used for monitoring and controlling heater temperature while the other thermocouple monitors and controls the internal reactants temperature.

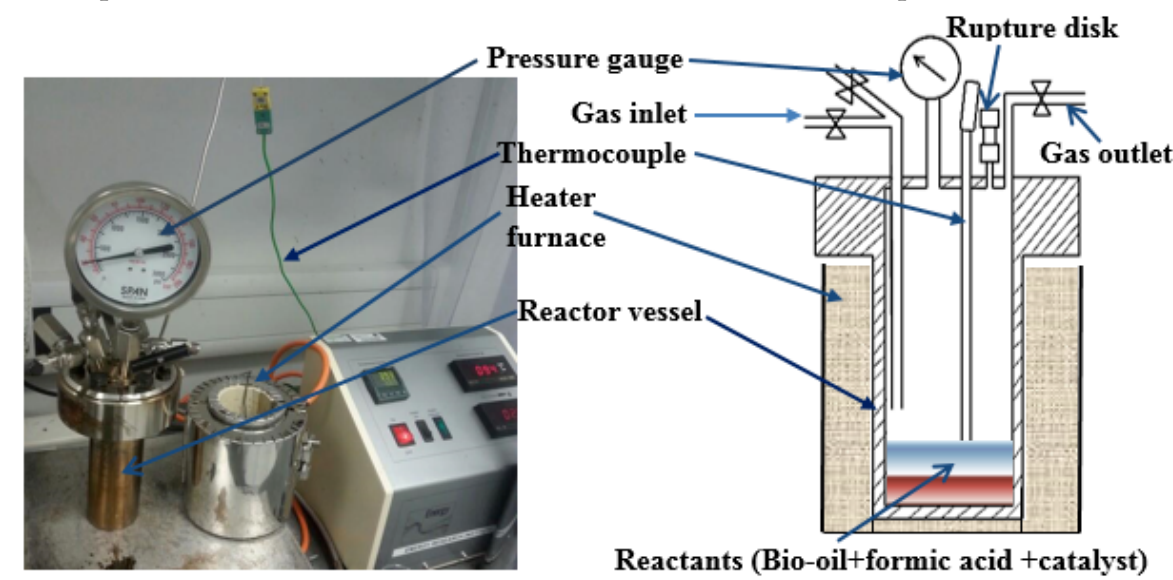

Figure 1: Components of the batch reactor 


\section{Materials}

Due to the large quantity of bio-oil required for this project, a commercial sample of bio-oil from a single-batch fast pyrolysis run was obtained from Catal (UK) limited (Onwudili and Williams, 2016) and was subsidised with bio-oil produced from pyrolysis of wood pellets at the University of Leeds. Alumina catalysts, 5 wt\% of: platinum, rhodium, ruthenium, nickel were obtained from Sigma-Aldrich company. The catalysts were pulverized and sieved to less than $125 \mathrm{\mu m}$ particle size since they were large pellets (1 mm pellets). Formic acid was used as hydrogen donor. $99 \%$ pure dichloromethane used as extraction solvent was bought from Sigma-Aldrich Company, UK.

\section{Experimental procedure}

$3 \mathrm{~g}$ of bio-oil was loaded into the batch type reactor followed by $2 \mathrm{~g}$ of formic acid and $1 \mathrm{~g}$ of the catalyst. Other two loadings were done with $3 \mathrm{~g}$ bio-oil but with formic acid (FA) and with no formic acid (BOR). The reactor was then mounted on the heater ready for the reforming process and purged with nitrogen gas for around 5 minutes to remove any trace of oxygen in the reactor and the valves carefully closed. The heater was turned on and the reactor heated at the rate of $16^{\circ} \mathrm{C}$ min-1. The reforming process was carried out at temperatures of $250{ }^{\circ} \mathrm{C}$ and $30{ }^{\circ} \mathrm{C}$ both for $60 \mathrm{~min}$ for all the components. After reforming, the reactor was removed from the heater and cooled using a fan for about $60 \mathrm{~min}$. The final ideal temperature and pressure was then recorded before sampling the gas and the extraction of the bio-oil to help in calculating the mass of the gases produced using ideal gas equation and Henry's law.

\section{Sampling the products}

Samples of the gas produced were then taken using syringe for analysis of the hydrocarbons and permanent gases. The reactor vessel was then dismantled from the head and oil extraction done after taking both the resulting final weight of the reactor vessel and the head. The mass of the gas produced was then calculated from the mass difference. Bio-oil extraction was then done by carefully separating all the char formed and catalyst by washing through with aliquot of dichloromethane (DCM) as a solvent. All the contents were thoroughly mixed and carefully filtered via weighed Whatman filter paper to get the solids and biooil solvent mixture separately. The solids were then allowed to dry and the weight noted.

\section{Analysis of the gases}

Gas tight syringe was used to obtain the gas products from the reaction. To analyse nitrogen, hydrogen, carbon monoxide and oxygen, $0.2 \mathrm{ml}$ of the gas sample was injected into a gas chromatograph (GC/TCD-Varian CP-3380) having argon as a carrier gas with two packed stainless steel columns and two thermal conductivity detectors. The column had a packing of 60-80 mesh molecular sieve and is $2 \mathrm{~m}$ long with a diameter of $2 \mathrm{~mm}$. A similar size of the column was used for the analysis of carbon dioxide but with a different packing material of Haysep 80-100 mesh but with a sample injection of $1.0 \mathrm{ml}$. For permanent gases, the oven temperature was held constantly at $30{ }^{\circ} \mathrm{C}$ while filament temperature held at $160{ }^{\circ} \mathrm{C}$ with injector temperature at $120{ }^{\circ} \mathrm{C}$. In the 
case of $\mathrm{C} 1$ to $\mathrm{C} 4$ hydrocarbons, $0.2 \mathrm{ml}$ of the gas sample was injected into the gas chromatograph and analysed using a different chromatograph with flame ionisation detector (Varian CP-3380-GC/FID). Here, nitrogen was used as a carrier gas with a $2 \mathrm{~m}$ long and $2 \mathrm{~mm}$ diameter stainless steel column having 80 100 mesh Hysep packing. The temperature program of the gas chromatograph was such that the injector and the detector were held at $150{ }^{\circ} \mathrm{C}$ and $200{ }^{\circ} \mathrm{C}$ respectively with a start of $60{ }^{\circ} \mathrm{C}$ for $3 \mathrm{~min}, 60-100{ }^{\circ} \mathrm{C}$ at $10{ }^{\mathrm{o}} \mathrm{C} / \mathrm{min}$ then holding at $100{ }^{\circ} \mathrm{C}$ for $3 \mathrm{~min}, 100-120{ }^{\circ} \mathrm{C}$ at $20{ }^{\circ} \mathrm{C}$ min- 1 and finally holding at 120 ${ }^{\mathrm{o}} \mathrm{C}$ for $9 \mathrm{~min}$.

\section{Bio-oil water content analysis}

Karl Fischer titration was used to determine water content in the bio-oil. About $5 \mathrm{~g}$ methanol was added to a given amount of liquid sample to make it homogenous. After setting the Karl Fischer instrument, about $0.8 \mathrm{ml}$ of each and every reformed bio-oil was injected separately into the instrument's titration cell to determine the percentage amount of water present in each and every reformed bio-oil. The percentage water in each sample was then identified after the run.

\section{Liquid product analysis}

Analysis of the oil was done using liquid gas chromatograph coupled with flame ionisation detector (Varian 430 GC FID). The instrument had split/splitless injection port. The ZB-1 capillary column where analysis was carried out had $0.5 \mathrm{\mu m}$ solid phase thickness and was $30 \mathrm{~m}$ long x $0.53 \mathrm{~mm}$ i.d. The carrier gas was hydrogen which had a constant flow rate of $1.0 \mathrm{~mL}$ every minute. The oil sample injection volume was $2.0 \mu \mathrm{L}$. The temperature programme of the column was such that the heating rate was $5{ }^{\circ} \mathrm{C}$ min- 1 from $40{ }^{\circ} \mathrm{C}$ to 310 ${ }^{\mathrm{o}} \mathrm{C}$. Calibration of the system was done using aromatic and poly-cyclic aromatic hydrocarbon standards.

\section{Elemental analysis}

The elements existing in the crude bio-oil and the reformed bio-oil were determined as regards the contents of carbon, hydrogen, nitrogen and sulphur using CHNS analyser. The instrument Carlo Erba Flash EA 1112 compact analyser used automatically determines CHNS present in the samples. Depending on the corresponding linear working range of the instrument, samples between 3.0 $\mathrm{mg}$ and $4.5 \mathrm{mg}$ were used.

\section{Analysis of the char}

The yield of the char was obtained by ashing $0.5 \mathrm{~g}$ of the solid residue in a furnace at $750{ }^{\circ} \mathrm{C}$ for $3 \mathrm{hr}$. The amount of char was then calculated by weight difference.

\section{Results And Discussion}

Four metal catalysts ( $5 \mathrm{wt} \%$; $\mathrm{Ru}, \mathrm{Rh}, \mathrm{Pt}$ and $\mathrm{Ni}$ ) were chosen having alumina supports for investigation. Experiments were also done with setups with 
only bio-oil (BOR) and, bio-oil and formic acid (FA). The catalysts chosen are known for being active in the hydrodeoxygenation processes (Sheu et al., 1988). The product yields, water, gas, char and oil were determined experimentally and are as shown on Figures 2 and 3.Different temperatures yielded varying amounts of char, bio-oil, water and gas. High amount of char was experienced with application of high temperature $\left(300^{\circ} \mathrm{C}\right)$ while low amount of char was observed with lower temperature $\left(250^{\circ} \mathrm{C}\right)$, a similar observations was made by Wildschut (2009b). When only bio-oil was used, a higher temperature gave rise to lower biooil yield but with high char, water and gas products.

Gas production also varied with temperature. The trend of gas yield with temperature was unpredictable but BOR, FA and Rh showed higher gas yield when temperature was increased from $250{ }^{\mathrm{O}} \mathrm{C}$ to $300{ }^{\mathrm{O}} \mathrm{C}$.Several reactions are responsible for the formation of the gaseous phase. Formic acid which decomposes when supplied with heat in the presence of water to give carbon dioxide and hydrogen gases contributes to the gas phase build up. It is noted that the amount of the carbon dioxide gas produced at $300{ }^{\circ} \mathrm{C}$ was considerably higher than the amount of the carbon dioxide gas produced at $250^{\circ} \mathrm{C}$ (Table 1). Formation of $\mathrm{CO} 2$ and $\mathrm{CO}$ confirms that there was much of carboxylation of oxygenates present taking place coupled by carbonylation. Among all the catalysts used, Pt exhibited the highest decarboxylation ability for organic acids in application of all the temperature.

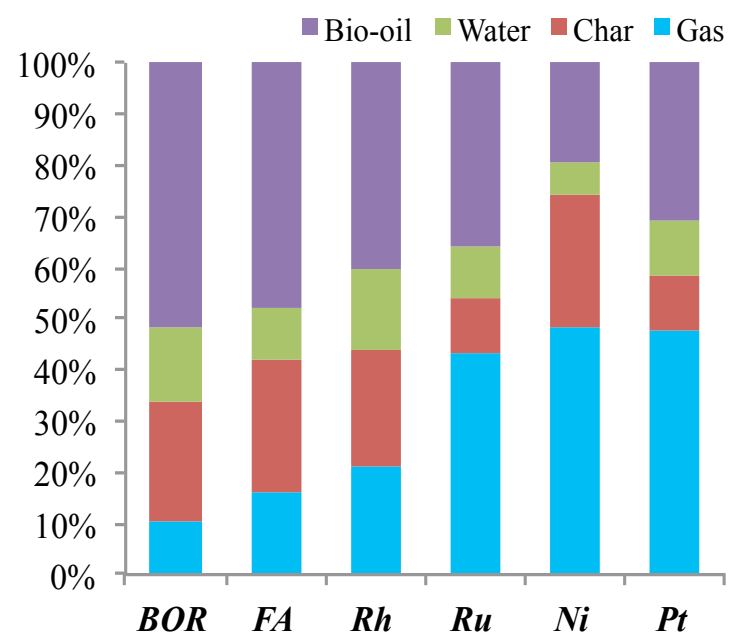

Figure 2: Catalytic hydrothermal treatment product spectrum at $250^{\circ} \mathrm{C}, 1 \mathrm{hr}$

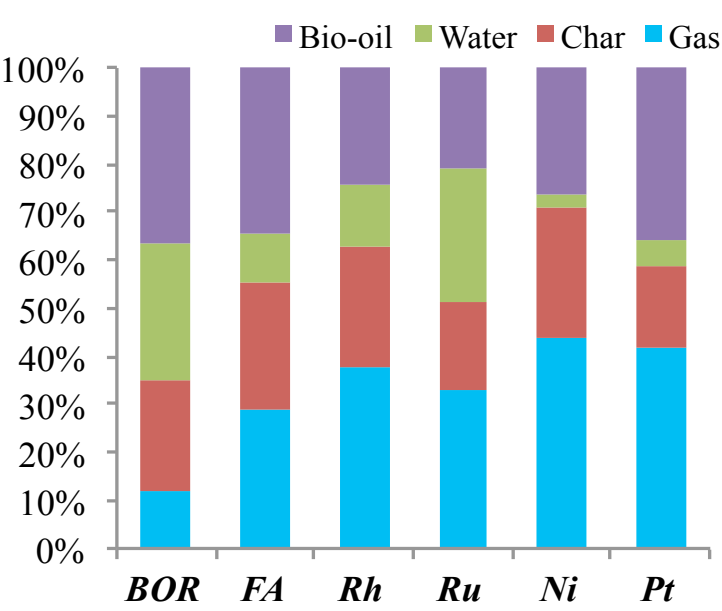

Figure 3: Catalytic hydrothermal treatment product spectrum at $250^{\circ} \mathrm{C}, 1 \mathrm{hr}$

Table 1: Composition of the gaseous phase at different temperatures

\begin{tabular}{|c|c|c|c|c|c|c|c|c|}
\hline \multirow{2}{*}{ Condition } & \multicolumn{4}{|c|}{$250{ }^{\mathrm{o}} \mathrm{C}$} & \multicolumn{4}{c|}{$300{ }^{\mathrm{O}} \mathrm{C}$} \\
\cline { 2 - 11 } & $\mathrm{H}_{2}$ & $\mathrm{CO}$ & $\mathrm{CO}_{2}$ & $\mathrm{C}_{1}-\mathrm{C}_{4}$ & $\mathrm{H}_{2}$ & $\mathrm{CO}$ & $\mathrm{CO}_{2}$ & $\mathrm{C}_{1}-\mathrm{C}_{4}$ \\
\hline Bio-oil & 7.47 & 12.81 & 76.89 & 2.83 & 5.01 & 11.912 & 81.54 & 1.54 \\
\hline $\mathrm{FA}$ & 24.74 & 30.64 & 44.29 & 0.33 & 21.09 & 25.00 & 53.31 & 0.60 \\
\hline $\mathrm{Ru}$ & 26.69 & 7.13 & 63.17 & 3.02 & 23.23 & 6.631 & 66.08 & 4.06 \\
\hline $\mathrm{Rh}$ & 27.41 & 27.52 & 44.72 & 0.35 & 20.62 & 25.010 & 53.98 & 0.31 \\
\hline $\mathrm{Ni}$ & 29.86 & 17.12 & 52.43 & 0.58 & 23.68 & 18.93 & 57.15 & 0.24 \\
\hline $\mathrm{Pt}$ & 32.12 & 0.00 & 67.40 & 0.48 & 27.02 & 4.29 & 68.09 & 0.60 \\
\hline
\end{tabular}


The key reaction which took place in all the reactors where formic acid was used is hydrodeoxygenation reaction where oxygenates in the complex compounds lost oxygen inform of hydroxyl radical in a reaction to form water (Mortensen et al., 2011). This is basically where water produced in the process came from. Another gaseous component of the spectrum was hydrogen gas; this is as a result of excess hydrogen which did not fully react after decomposition of formic acid. In this research, the consumption rate of hydrogen at a lower temperature of 250 ${ }^{\mathrm{o}} \mathrm{C}$ was lower between $55 \%$ and $65 \%$ compared to when the temperature was raised to $300{ }^{\circ} \mathrm{C}$ that increased the consumption rate between $62 \%$ and $75 \%$.

\section{Elemental analysis of reformed bio-oil}

Table 2 shows that all the conditions used changed the elemental composition of the bio-oil. Compared with the raw bio-oil elemental composition, Ru emerged to be the best in reducing the oxygen content in the bio-oil. $\mathrm{Ru}$ reduced the original oxygen weight content by $42.12 \%$ giving final oxygen content of $28.50 \mathrm{wt}$ $\%$. In all the conditions, there was increased amount of both the carbon and hydrogen wt\% with decreased oxygen wt\%. This is an indication of the improved bio-oil quality.

Table 2: Elemental analysis of $3 \mathrm{~g}$ bio-oil at $250^{\circ} \mathrm{C}$ compared to the raw bio-oil for $60 \mathrm{~min}$

\begin{tabular}{|c|c|c|c|c|c|}
\hline \multicolumn{2}{|c|}{ Condition } & $\begin{array}{l}\text { Nitrogen } \\
\text { (wt \%) }\end{array}$ & $\begin{array}{l}\text { Carbon } \\
(\text { wt \%) }\end{array}$ & $\begin{array}{l}\text { Hydrogen } \\
\text { (wt \%) }\end{array}$ & $\begin{array}{l}\text { Oxygen } \\
(\text { wt \%) }\end{array}$ \\
\hline \multicolumn{2}{|c|}{ Raw bio-oil } & $<0.01$ & 41.00 & 6.10 & 52.90 \\
\hline \multirow{4}{*}{ 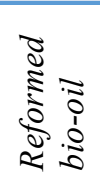 } & $F A$ & 0.12 & 61.40 & 7.39 & 31.09 \\
\hline & $\boldsymbol{R h}$ & 0.08 & 48.43 & 6.71 & 44.78 \\
\hline & $R u$ & 0.13 & 64.66 & 6.71 & 28.50 \\
\hline & $N i$ & 0.11 & 62.63 & 6.93 & 30.33 \\
\hline
\end{tabular}

\section{Carbon balance}

The products formed were quantified into char, gas phase and treated bio-oil. With the elemental composition of the untreated and treated bio-oil known and the yields in the char and the gas, the carbon recovery is calculated. The carbon weight percent in the char, gas and the treated bio-oil was analysed and the carbon balance reached. Reformed bio-oil treated by Ni, Pt and Ru treated at 250 ${ }^{\mathrm{o}} \mathrm{C}$ for $60 \mathrm{~min}$ showed perfect carbon mass balance which indicated a good trend with minimal carbon loss of up to $9 \mathrm{wt} \%$ with the carbon recovery of Ni-91.68, Ru-96.19, Pt-94.34. With the carbon-wt\% of the char and the gases known from the analysis, amount of the carbon - wt\% remaining in the treated bio-oil is easily calculated for other conditions assuming negligible carbon losses; as

\section{$\%$ carbon in reformed bio-oil $=100 w t \%-(\%$ carbon in the char $+\%$ carbon in the gas)}

Generally, the carbon recovery in the bio-oil was low at higher temperature $\left(300^{\circ} \mathrm{C}\right)$ than at lower temperature $\left(250^{\circ} \mathrm{C}\right)$ with much carbon in either char or gas. The carbon balance at higher temperature is relatively poor since mild 
cracking is likely to take place which results into lighter compounds which can easily evaporate during the process of evaporating solvents. The results showed that, at lower temperature $\left(250^{\circ} \mathrm{C}\right)$, the treated bio-oil contains more carbon than that at higher temperature $\left(300^{\circ} \mathrm{C}\right)$, a fact supported by Duan and Savage (2011).

\section{Oil analysis and effects of temperature}

The oil analyses results from the GC/FID was categorised into three fractions according to their percentage peak areas for easy explanation. The categories were; light compounds (compound eluting up to phenol - excluding solvent peak), medium compounds (compounds eluting between phenol and naphthalene) and heavy compounds (compounds eluting after naphthalene). The major compound in the light fraction was cyclohexanol with up to $40 \%$ peak area. When oil analysis was done at $250{ }^{\circ} \mathrm{C}$, all the catalysts displayed improved oil qualities compared to the raw bio-oil as shown on Figure 4 . $\mathrm{Ru}$ emerged to have the highest composition of the lighter compounds (up to phenol) with $88.5 \%$ of the recovered oil. Other catalysts also gave good amounts of lighter components $(\mathrm{Rh}=70 \%, \mathrm{Ni}=64.2 \%, \mathrm{Pt}=57.4 \%)$ but with some relatively large amounts of medium and heavy components. It therefore implies that, the oxygenated compounds in the bio-oil treated with ruthenium catalyst were substantially reduced.

When oil analysis was done for the reforming at $300{ }^{\circ} \mathrm{C}$, there was still improved composition of the reformed oil but the fraction of the lighter compounds reduced with increased composition of medium and heavy compounds (Figure 5). It therefore follows that $\mathrm{Ru}$ has emerged very promising in producing bio-oil with low oxygenated compounds with majorly lighter compounds but at a condition of low temperature. In all the scenarios, the catalysts used at a lower temperature produced low medium and heavy products than at higher temperatures. A higher temperature is coupled with thermal cracking that contributes to heavy and medium weight compounds which means that, the 300 ${ }^{\mathrm{o}} \mathrm{C}$ temperature was capable of cracking the light compounds further into gas while at the same time promoting secondary reactions such as condensation resulting into heavy molecular weight compounds (Wildschut et al.,2009a)

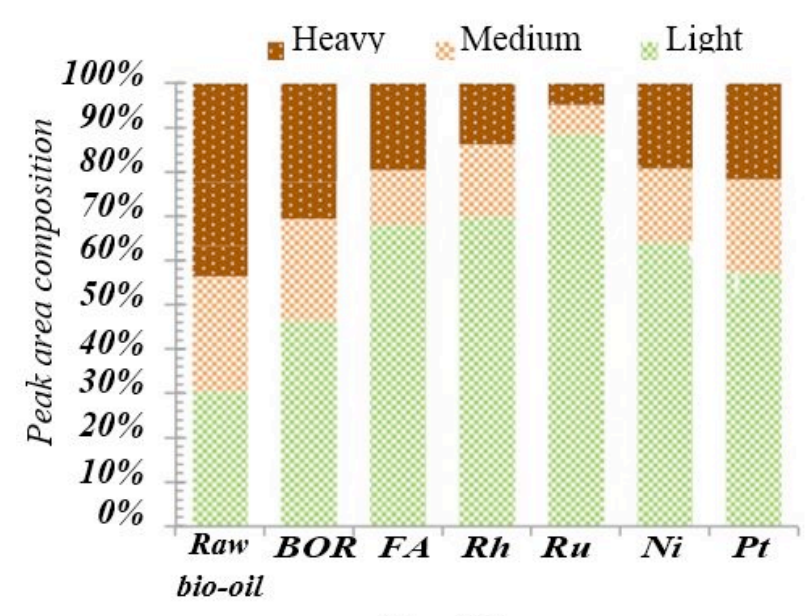

Condition

Figure 4: Percentage peak area composition of the reformed bio-oil at $250{ }^{\circ} \mathrm{C}$

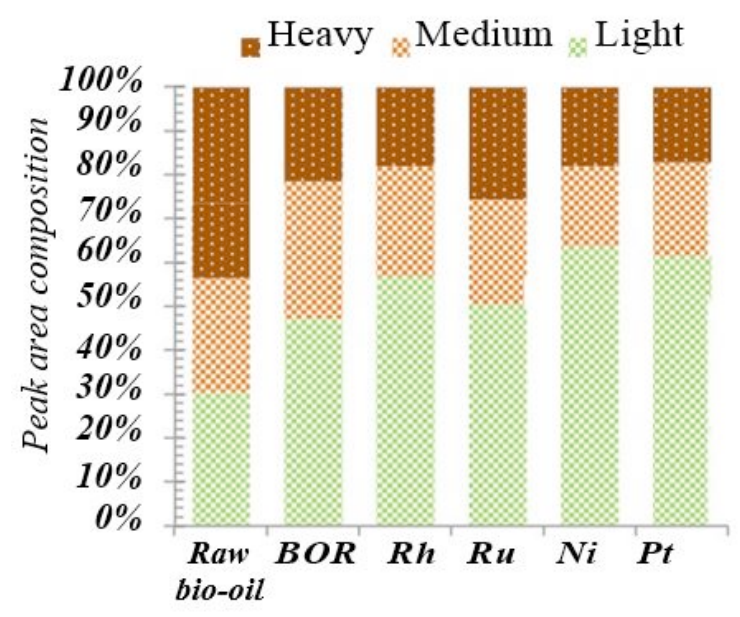

\section{Condition}

Figure 5: Percentage peak area composition of the reformed bio-oil at $300{ }^{\circ} \mathrm{C}$ 


\section{Conclusions}

Catalytic hydrothermal treatment has proved to be very effective in altering the chemical and elemental composition of the pyrolysis bio-oil. Two different reforming temperatures were compared, $250{ }^{\mathrm{o}} \mathrm{C}$ and $300{ }^{\mathrm{o}} \mathrm{C}$ with the use of different catalysts. Using catalysts showed improved bio-oil quality. Ruthenium catalyst had the best reduction of the elemental composition of oxygen and gave majorly the bio-oil with lighter compounds at $250^{\circ} \mathrm{C}$. It therefore follows that $\mathrm{Ru}$ is a very promising catalyst with the best oxygen reduction capability. Investigation of temperature shows that higher temperature did not give desired bio-oil qualities since the oil product was dominated by medium and heavy compounds. $\mathrm{Ru}$ at $250{ }^{\circ} \mathrm{C}$ had a total weight $\%$ of 11.49 for both light and medium compounds while at $300{ }^{\circ} \mathrm{C}$, the total weight $\%$ composition of both medium and light compounds was 49.5\%. Higher temperature favoured production of both high amount the gas and the char coupled with very big carbon loss in both the char and the gas. High temperature also leads to cracking of the alkenes into higher alkanes a situation which further contributes to more carbon loss even in form of the gases. With the positive results using catalysts in the improvement of the bio-oil quality (increased hydrogen wt \%, carbon wt \% and reduced oxygen wt \%), it is a clear indication that catalytic hydrothermal reforming is the desirable way to produce transport fuel from pyrolysis oil.

\section{Acknowledgement}

My sincere appreciation goes to Dr. Mohamad Nahil of Energy Research Institute (University of Leeds) for his interest on me during the early stages of this work.

\section{References}

Balat, M., Balat, M., Kırtay, E., \& Balat, H. 2009. Main routes for the thermo- conversion of biomass into fuels and chemicals. Part 1: Pyrolysis systems. Energy Conversion and Management.50 (12), pp. 3147-3157.

Bridgwater, A.V.2012. Review of fast pyrolysis of biomass and product upgrading: Biomass and Bio energy.38 (2012).pp, 68-94

Carpenter, D.Westover, T.L, Jablonski.W.2014. Biomass feedstocks for renewable fuel production: a review of the impacts of feedstock and pretreatment on the yield and product distribution of fast pyrolysis bio-oils and vapors. ."Green Chemistry" 16(2), pp. 384-406.

Duan, P., \& Savage, P. E. (2011). Catalytic treatment of crude algal bio-oil in supercritical water: optimization studies. Energy \& Environmental Science. 4(4), pp. 1447-1456

Grirard, P and Blin, J. 2005. Environmental, health and safety aspects related to pyrolysis. In:Bridgwater AV, editor. Fast pyrolysis of biomass a handbook, vol. 3.pp, 1-217. Newbury,UK: CPL Press.

Huber, G.W., Iborra,S and Corma,A.2006. Synthesis of transportation fuels from biomass: chemistry, catalysts, and engineering. Chem. Rev. 106(9).pp, 4044-4098.

Maschio,G. Koufopanos,C and Lucchesi,A. 1992. Pyrolysis, a Promising Route for Biomass Utilization:Bioresource Technology. 42 (3), pp. 219-231.

Mortensen, P.M, Grunwaldt J, Jensen, P.A, Knudsen, K.G, Jensen AD. 2011. A review of catalytic upgrading of bio-oil to engine fuels. Applied Catalysis A: General .407 (1).pp, 1-19. 
Onwudili, J. A., \& Williams, P. T. 2016. Catalytic conversion of bio-oil in supercritical water: Influence of $\mathrm{RuO} 2 / \gamma-\mathrm{Al} 2 \mathrm{O} 3$ catalysts on gasification efficiencies and bio-methane production. Applied Catalysis B: Environmental,180, 559-568.

Parapati, D.R and Steele, P.H. 2014. Catalyst Screening for Single-Stage Catalytic Hydro processing of Bio-oil in a Continuous Packed-bed Reactor for the Production of Hydrocarbon Fuel. Journal of forest products \& industries. 3(6).pp, 266-277.

Sheu, Y. H. E., Anthony, R. G., \& Soltes, E. J. 1988. Kinetic studies of upgrading pine pyrolytic oil by hydrotreatment. Fuel processing technology, 19(1), 31-50.

Tsai, W. T., Lee, M. K., \& Chang, Y. M. 2007. Fast pyrolysis of rice husk: product yields and compositions. Bioresource Technology.98 (1), pp. 22-28.

Wildschut, J., Arentz, J. Rasrendra, C.B., Venderbosch, R.H and Heeres, H.J.2009a.Catalytic hydrotreatment of fast pyrolysis oil: model studies on reaction pathways for the carbohydrate fraction.Environmental progress \& sustainable energy.28 (3), pp. 450-460.

Wildschut,J., Mahfud, F.H., Venderbosch, R.H.,Heeres. H.J. (2009b). Ind. Eng. Chem. Res.48 1032410334.

Yaman, S. 2004. Pyrolysis of biomass to produce fuels and chemical feedstocks: Energy Conversion and Management. 45 (5), pp. 651-671.

Zhang, Q., Chang, J., Wang, T., \& Xu, Y. 2007. Review of biomass pyrolysis oil properties and upgrading research. Energy conversion and management. 48(1), pp.87-92. 